\title{
Improving alloreactive CTL immunotherapy for malignant gliomas using a simulation model of their interactive dynamics
}

\author{
Natalie Kronik • Yuri Kogan · Vladimir Vainstein • \\ Zvia Agur
}

Published online: 7 December 2007

(C) Springer-Verlag 2007

\section{Erratum to: Cancer Immunol Immunother} DOI 10.1007/s00262-007-0387-z

Two numerical errors appear in the Appendix to the article. The correct value of $a_{C, M_{\text {II }}}$ should be $2 \times 10^{5}$ cells $/ \mathrm{h}$. This correction does not affect any of the article's conclusions.
Note that in the simulations of unsuccessful treatments, the final tumor load is predicted to be slightly lower than previously calculated, but to remain well within the lethal range.

The other error in the Appendix is typographical. In the calculation of $\mu_{C}$, the denominator should be $93.6 \mathrm{~h}$.

The online version of the original article can be found under doi:10.1007/s00262-007-0387-z.

N. Kronik · Y. Kogan · V. Vainstein $\cdot$ Z. Agur $(\square)$

Institute for Medical BioMathematics (IMBM), 10 Hate'ena St,

P.O. Box 282, Bene Ataroth 60991, Israel

e-mail: agur@imbm.org

N. Kronik

e-mail: natalie@imbm.org 